\title{
Chapter 10 \\ Optimal Energy Portfolios \\ in the Electricity Sector: Trade-Offs \\ and Interplay Between Different \\ Flexibility Options
}

\author{
Steffi Schreiber, Christoph Zöphel, and Dominik Möst
}

\begin{abstract}
The expansion of renewable energy sources (RES) and the electrification of demand side sectors raise the need for power system flexibility. The following model-based analysis illustrates the complexity of the European energy system transformation with pathways regarding the RES expansion, sector coupling, and different levels of flexibility provision. Differences occur concerning the optimal mix of flexibility options between the moderate and ambitious climate target scenarios. Dispatchable back-up capacities are necessary, also in presence of high RES shares. Here, $\mathrm{CO}_{2}$ prices influence the role of low-carbon technologies. Due to cross-sectoral interactions, energy storages have a limited value. For the ambitious scenarios, the emission reductions come close to the Green Deal targets of the European Commission, while levelized costs of electricity increase moderately compared to the less ambitious scenario.
\end{abstract}

\subsection{Introduction}

The power sector is responsible for around $25 \%$ of total greenhouse gas (GHG) emissions in Europe (European Commission 2011a). Regarding the overall emission reduction targets, the European power sector has a crucial role since several low-carbon technologies are already technically available at comparably affordable costs (Zöphel et al. 2019). To achieve a cross-sectoral low-carbon European energy system two main challenges arise for the power system. First, future electricity generation will be based mainly on weather-dependent renewable energy sources (RES) (Irena 2018). Balancing requirements will rise as well as electricity supply is becoming increasingly fluctuating. Thus, the former load following power system has to transform into a system, in which both, supply and demand need to be flexible (Müller and Möst 2018). Second, with the electrification of the demand side sectors

S. Schreiber · C. Zöphel · D. Möst ( $\varangle)$

Chair of Energy Economics, Technische Universität Dresden, Dresden, Germany

e-mail: Dominik.Moest@tu-dresden.de 
to achieve European energy system-wide decarbonization goals, a significant expansion of low-carbon electricity supply options becomes even more crucial and will strongly influence the transformation of the electricity system (Brown et al. 2018).

Against the background of the energy political aim for decarbonization, the European electricity market plays a decisive role in providing both, the integration of large shares of RES and the provision of electricity for a cross-sectoral energy system (Zöphel et al. 2018). A technology-neutral electricity market is of high importance, since a broad range of flexibility options with different applications including sector coupling technologies exist (Bertsch et al. 2016). Therefore, an optimal mix of these technologies strongly depends on the framework conditions of the energy system, particularly in a cross-sectoral system. Within the REFLEX project, different possible pathways with moderate and ambitious decarbonization goals are developed to analyze the measures required to achieve these targets as well as to improve the understanding of the resulting cross-sectoral interactions. Besides different RES shares, various levels and implementations of sector coupling are therefore examined in the three REFLEX scenarios: Mod-RES, High-RES decentralized, and High-RES centralized (cf. Chapter 2).

From a system perspective, the flexibility requirements arising from the integration of RES as well as from the cross-sectoral electrification are defined by the level and pattern of the residual load (here as difference between electricity demand and fluctuating RES). The techno-economical characteristics of flexibility options enable different applications to balance the residual load. While dispatchable power plants can ramp up and down their electricity generation to provide electricity when needed, storages, demand side management (DSM), and transmission lines provide flexibility by shifting electricity temporally and regionally. Additionally, sector coupling technologies increase the electricity demand and thus raise the use of RES surplus energy (Michaelis et al. 2017). The transformation of the electricity system discussed above as well as the broad range of available technologies lead to complex interactions and competition between these flexibility options, not only within electricity markets, but also cross-sectoral.

The objective of the chapter at hand is to analyze optimal combinations of flexibility options within the REFLEX scenario framework from an electricity market perspective. Therefore, ELTRAMOD is applied, a bottom-up linear optimization electricity market model with model-endogenous investments and dispatch decisions for flexibility options, including various power plants, different types of storage technologies, and different power-to-x applications. ${ }^{1}$ Since in the present chapter, the application of ELTRAMOD is embedded in the energy modeling system (EMS) of the REFLEX project (cf. Chapter 3), several model couplings have an impact on the optimal investment and dispatch of the observed flexibility options. With the model-based analysis, optimal combinations of relevant technologies are calculated to assess the role of different flexibility options against the background of the

\footnotetext{
${ }^{1}$ Mathematical equations and detailed descriptions of ELTRAMOD are introduced in Zöphel et al. (2019), Hobbie et al. (2019), Ladwig (2018) and Schubert (2016).
} 
scenario-specific assumptions. In a cross-sectoral energy system, interactions with other energy demand and supply sectors are of particular interest.

In the following Sect. 10.2 main assumptions regarding the scenario framework and data input are presented. Furthermore, relevant modeling interfaces with energy system models in the REFLEX EMS are discussed. Thereafter, in Sect. 10.3 the results regarding the optimal mix of flexibility options are analyzed. In addition to the discussion of resulting emission reductions, further insights are given by selected sensitivity analyses. Furthermore, the role of energy storages in the electricity market is analyzed in detail regarding their competition with residential flexibility options. Moreover, the influence of higher RES capacities, to cover the additional electricity demand resulting from sector coupling in the European energy system, is assessed. In Sect. 10.4 the scenario-specific levelized cost of electricity (LCOE) are examined. Based on the results, a discussion and conclusion is formulated in Sect. 10.5.

\subsection{Data Input and Model Coupling}

The model specifications regarding ELTRAMOD are summarized briefly, since a more detailed model description as well as references to application examples are presented in Chapter 3. The focus of this section rather lies on the input assumptions and underlying model couplings, crucial for understanding the ELTRAMOD results.

ELTRAMOD (Electricity Transshipment Model) is a bottom-up electricity market model. It allows fundamental analysis of the European electricity market. The Net Transfer Capacity (NTC) between regions is considered while the electricity grid within one country is neglected. Each country is treated as one node with countryspecific hourly time series of electricity and heat demand as well as renewable feed-in. ELTRAMOD is a linear optimization model, which calculates the costminimal investments and dispatch in power plant capacities, storage facilities, and power-to-X-technologies (i.e., power-to-heat, power-to-gas). The set of conventional power plants consists of fossil fuel-fired, nuclear, and hydro plants. Additionally, fossil fuel-fired carbon capture and storage (CCS) technologies are included as lowcarbon technologies. Further, flexibility options such as adiabatic compressed air energy storages (A-CAES), lithium-ion batteries, redox-flow batteries, power-toheat (heat pumps), and power-to-gas applications (electrolyzers) are implemented. Country-specific RES capacities, their expansion pathways and generation in hourly resolution are exogenous inputs for the present analysis. All technologies are represented by different technological characteristics, such as efficiency, emission factors, ramp rates, and availability. Technology-specific economic parameters are annualized capacity specific investment costs, operation and maintenance costs, fixed costs as well as costs for ramping up and down the generation. Additionally, hourly prices for $\mathrm{CO}_{2}$ allowances and hourly wholesale fuel prices are implemented in ELTRAMOD. The geographical scope covers the member states of EU-27, Norway, Switzerland, United Kingdom, and the Balkan countries. 


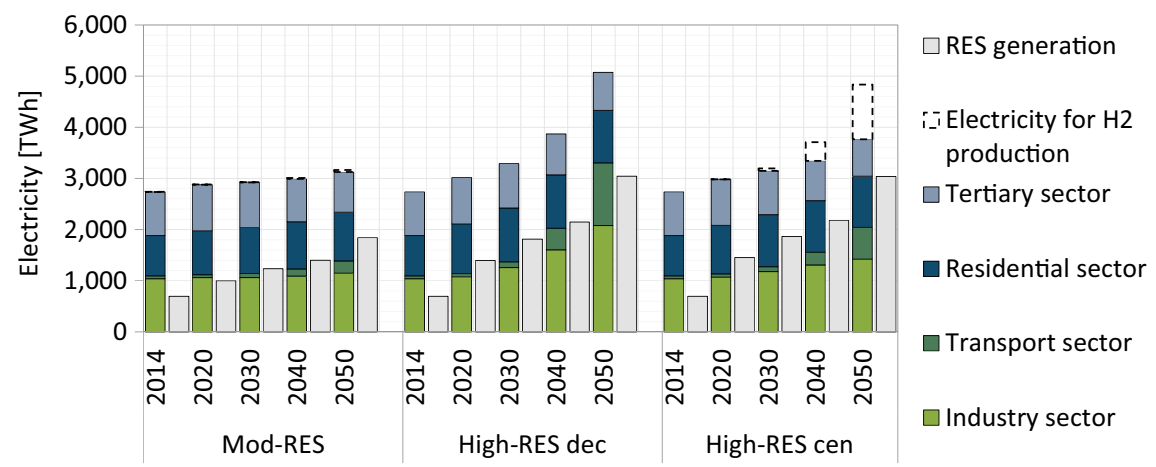

Fig. 10.1 RES electricity generation and electricity demand across all modeled countries (EU27, Norway, Switzerland, United Kingdom, and the Balkan countries) (Source Data for the crosssectoral electricity demand according to own calculations by Fraunhofer ISI with the models FORECAST and ASTRA. Data for RES generation profiles according to own calculations by KIT-IIP as described in Slednev et al. [2018])

Regarding the data input, different levels of renewable electricity generation from $\mathrm{PV}$ and wind power are introduced to account for a moderate (Mod-RES scenario) and ambitious (High-RES scenarios) RES expansion pathways until 2050. The RES expansion pathways as well as the respective hourly generation profiles are exogenous model input based on weather data and geo-information on land use (cf. Zöphel et al. 2019; Slednev et al. 2018). Regarding the RES generation, the High-RES decentralized scenario is characterized by a higher share of decentral PV rooftop power plants, while in the High-RES centralized scenario, wind offshore power has higher capacities. In the High-RES scenarios the RES share is calculated based on $80 \%$ of the considered countries' electricity demand in the year 2014, resulting in 3,000 TWh (cf. Fig. 10.1).

Within the REFLEX scenario framework the electricity demand is developing differently until 2050 , based on the assumed pathways in the energy demand sectors industry, residential, tertiary, and transport (cf. Chapter 6). The interfaces with TIMES-Heat-EU, ASTRA, FORECAST, and eLOAD influence the results of ELTRAMOD. Regarding the electrification of the heat sector, the heat demand for power-to-heat applications is restricted and derived from TIMES-Heat-EU results (cf. Chapter 12). In addition, combined heat and power plant (CHP) capacities, resulting from the model interface with TIMES-Heat-EU, are implemented in ELTRAMOD as minimum fuel-specific power plant installations. Furthermore, there are differences in the developments of the electricity demand and energy efficiency measures between each scenario due to the model coupling with ASTRA, FORECAST, and eLOAD. As illustrated in Fig. 10.1, the scenario-specific assumptions result in a comparably lower electricity system load in the Mod-RES scenario due to lower electrification levels of the energy demand for different end users (e.g., heat, industry, and mobility). Additionally, the REFLEX scenario framework influences the composition 
of the electricity demand. Besides the direct electricity usage in the industry, residential, tertiary, and transport sectors, the electricity demand for hydrogen production varies between the decentralized and centralized High-RES scenario. In the HighRES decentralized scenario, hydrogen demand for industry and transport is satisfied directly via decentral electrolysis and therefore increases electricity demand in the industry and transport sector. In contrast, in the High-RES centralized scenario, the hydrogen demand is covered model-endogenously in ELTRAMOD via central electrolyzers taking part in the electricity market.

For the scenario-specific model calculations with ELTRAMOD, the total system load is transformed into hourly load profiles smoothed by DSM measures from eLOAD for each scenario. As shown in Chapter 7, the potential of different DSM processes to flatten the residual load can be substantial. Since these applications are assumed to be applied decentralized, thus not participating in the wholesale electricity market, the value of additional market-based flexibility options represented in ELTRAMOD is restricted in the High-RES decentralized scenario.

The varying scenario-specific RES expansion and electricity demand pathways can be summarized when looking at the sorted residual load curves presented in Fig. 10.2. In the Mod-RES scenario (left), the average residual load continuously decreases until 2050 due to the RES expansion, with an increased frequency of low (and negative) residual loads. This development is restrained and reversed in the High-RES scenarios because of the significant increase in electricity demand from different sectors overlapping the RES expansion. As a result of the extensive

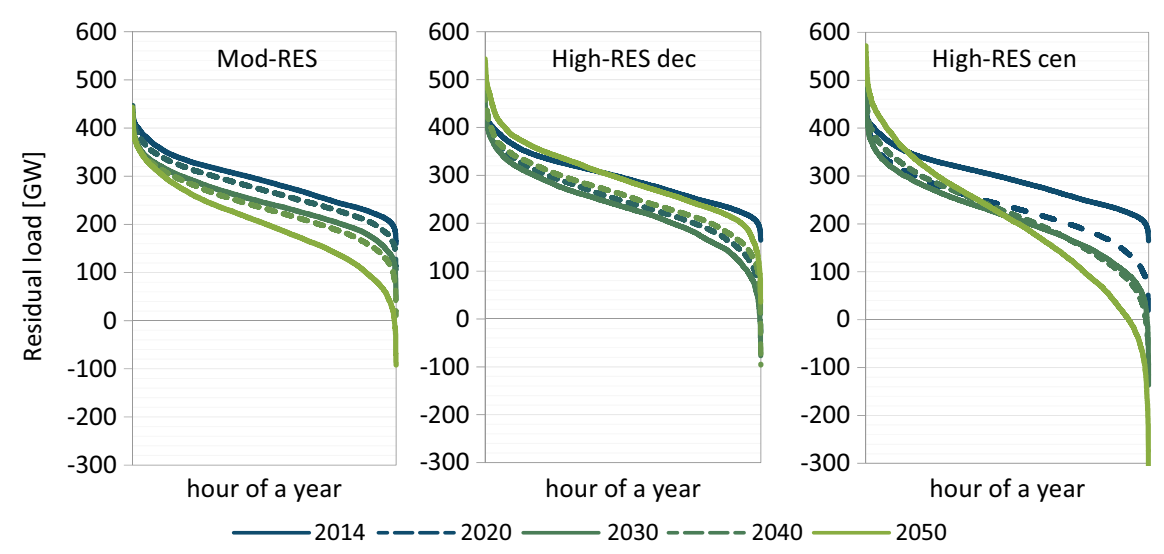

Fig. 10.2 Development of aggregated and sorted residual load curves across all modeled countries (EU-27, Norway, Switzerland, United Kingdom, and the Balkan countries). The residual load curve is defined as the difference between the system load and the intermittent electricity generation by wind and photovoltaic power plants (Load increase by power-to-gas is not included in the residual load curve of the High-RES centralized case due to the scenario definition. In this scenario, the hydrogen demand is covered model-endogenously in ELTRAMOD via optimal dispatch of central electrolyzers taking part in the electricity market) (Source Data according to own calculations. The hourly system load data are model outputs from eLOAD calculated by Fraunhofer ISI. The RES generation profiles are calculated by KIT-IIP as described in Slednev et al. [2018]) 
application of DSM in the residential sector, this effect is most significant in the HighRES decentralized scenario (middle). ${ }^{2}$ In the High-RES centralized scenario (right) the smoothing effect of DSM is lower and thus, the residual duration load curve has a steeper development. As mentioned before and in contrast to the decentralized scenario, load increase by power-to-gas is not included in the depicted residual load curve due to the scenario definition, which defines that the hydrogen demand is covered model-endogenously in ELTRAMOD via central electrolyzers taking part in the electricity market.

Besides the renewable expansion pathways, further central assumptions within the REFLEX scenario framework have an impact on the results presented here (cf. Chapter 2). Of high importance for the modeling results are scenario-specific $\mathrm{CO}_{2}$ prices reflecting the frameworks discussed in Chapter 2. $\mathrm{CO}_{2}$ price developments are based on the EU Reference Scenario (Capros et al. 2016). Further information on model input data can be found online at the REFLEX database. ${ }^{3}$ The input regarding the fuel and $\mathrm{CO}_{2}$ prices as well as the cost developments based on the technological learning curves strongly influence the model-endogenous decisions on optimal flexible technology combinations. Additionally, existing power plant decommissioning is assumed to be exogenous, based on power plant age.

\subsection{Optimal Investments in Flexibility Options}

Since the results regarding the sector coupling technologies are influenced by the cross-sectoral electricity demand for district heat (power-to-heat) and hydrogen (power-to-gas) within the REFLEX model coupling framework, the modelendogenous investments are largely restricted and the results for these technologies are presented first. More detailed analyses are presented regarding the power plant and storage investments, with additional sensitivity analyses in Sect. 10.4. In general, the results are depicted on an aggregated level for the energy systems of the EU-27, Norway, Switzerland, United Kingdom, and the Balkan countries.

\subsubsection{Sector Coupling Technologies}

Ideally, increased demand from sector coupling technologies coincide temporally with surpluses of RES electricity generation. From an electricity market perspective, heat pumps or electrolyzers for instance, may improve RES integration by

\footnotetext{
${ }^{2}$ The speed of RES expansion and electrification of demand side sectors have a substantial influence on the development of the residual load curve. In REFLEX, a range of different residual load curves is analyzed to assess the impact of different future developments. Results can be transferred depending on the developments in the real system.

${ }^{3}$ https://data.esa2.eu/tree/REFLEX.
} 
smoothing and increasing the residual load. During times with high RES feed-in and low electricity prices, a dispatch of power-to-x technologies to substitute intrasectoral fuels is most economical. Nevertheless, these applications are restricted by the availability of infrastructure (e.g., heat storages for heat pumps and electric boilers or hydrogen storages and pipelines for electrolyzers), but also by required full load hours to cover investment costs (Brunner et al. 2015). Despite techno-economic challenges, ambitious climate protection goals may increase the need for electricitybased substitutions of carbon-intensive fuels in different energy sectors. This energy policy-driven fuel switch is normatively described in the REFLEX scenarios and results in the assumptions described in the sections before. In the following, the electricity market-based optimal investments in power-to-x technologies are compared with those calculated for other sectors (cf. Fig. 10.3). For the district heat sector, heat pumps and electric boilers are the technologies included.

High shares of residential heat pumps (as a result of eLOAD calculations, cf. Chapters 6 and 7) can be observed, particularly in the High-RES decentralized scenario. Regarding the district heat systems, electric boilers have the highest capacities (cf. Chapter 12), particularly in the centralized scenario, since heat pumps are less beneficial due to higher specific investment costs. As a consequence of the higher heat demand in the High-RES centralized scenario, the overall power-to-heat capacities are the highest with around $300 \mathrm{GW}_{\mathrm{el}}$. These power-to-heat technologies are equipped with heat storages (cf. Chapter 12) and can be dispatched flexibly, mainly to enable the use of high RES feed-in phases (low residual load) with low electricity prices. The average power-to-heat full load hours are below 1,000 h/a.

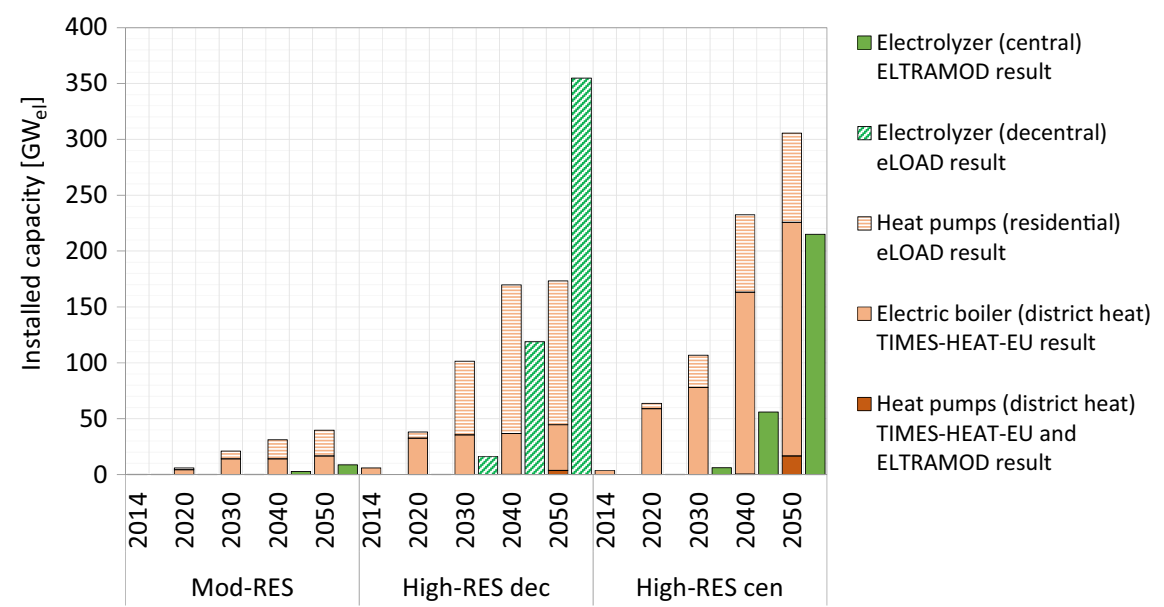

Fig. 10.3 Installed power-to-heat and power-to-gas technologies across all modeled countries (EU27, Norway, Switzerland, United Kingdom, and the Balkan countries) (Source Data according to own calculations by Fraunhofer ISI, AGH University Krakow, and TU Dresden with the models eLOAD, TIMES-Heat-EU, and ELTRAMOD) 
While in the Mod-RES scenario there is only a small demand for hydrogen, from 2030 on, the demand increases significantly in both High-RES scenarios. As mentioned before, the hydrogen provision for industry and transport varies between the decentralized and centralized scenario. The decentral onsite production requires around $350 \mathrm{GW}_{\mathrm{el}}$ electrolyzer capacity in the High-RES decentralized scenario (cf. Chapters 6 and 7). The optimal capacity for the central hydrogen production to cover the exogenous hydrogen demand in the High-RES centralized scenario is calculated model-endogenously with ELTRAMOD. In total, $200 \mathrm{GW}_{\mathrm{el}}$ are installed. The results show average full load hours of the electrolyzers above $6,000 \mathrm{~h} / \mathrm{a}$ illustrating the high specific investment costs for large-scale electrolyzers, which needs to be compensated by achieving high utilization rates. For the same reason, additional investments in hydrogen storages cannot be observed. Therefore, the dispatch of electrolyzers is rather inflexible.

\subsubsection{Power Plant Mix}

With total electricity generation capacities increasing up to $690 \mathrm{GW}$ in the Mod-RES scenario and up to $1,100 \mathrm{GW}$ in the High-RES scenarios, weather-dependent wind and PV power plants become the dominating electricity generation technologies in each REFLEX scenario. Dispatchable power plants enable the electricity provision in times when the feed-in of the fluctuating energy sources cannot satisfy electricity demand.

In Fig. 10.4, the model-endogenously added power plant capacities are presented together with the exogenously determined RES installations (cf. Section 2). In total, the High-RES decentralized scenario shows the highest power plant capacities (around 2,000 GW) due to the lower capacity credit, i.e., availability of PV, and higher electricity demand in this scenario. Furthermore, both the low capacity credit of the RES as well as the increasing electricity demand result in the need for additional dispatchable power plants. In each scenario, the fossil fuel-based capacities are decreasing until 2030 and 2040, respectively, while there is an increase until 2050 resulting from sector coupling.

In total, there are more fossil fuel-based technologies in the High-RES scenarios compared to Mod-RES scenario due to the higher (additional) electricity demand resulting from the sector coupling. Ensuing from the increasing $\mathrm{CO}_{2}$ prices, a fuel switch from emission-intensive to low-carbon technologies can be observed in the optimal power plant mix until 2050. Within the conventional power plant capacities, gas-fired plants achieve the highest shares, but also nuclear power plants remain an option (between $43 \mathrm{GW}$ and $65 \mathrm{GW}$ across all scenarios), despite relatively high investment costs. Furthermore, there is no final phase-out from coal and lignite, mainly due to must-run CHP capacities for the district heat sector. From 2040 on, CCS gains importance in the generation mix of the High-RES scenarios due to high $\mathrm{CO}_{2}$ prices and the corresponding need for emission reduction. In the High-RES decentralized scenario, around $203 \mathrm{GW}$ of gas-fired CCS technologies are installed, 


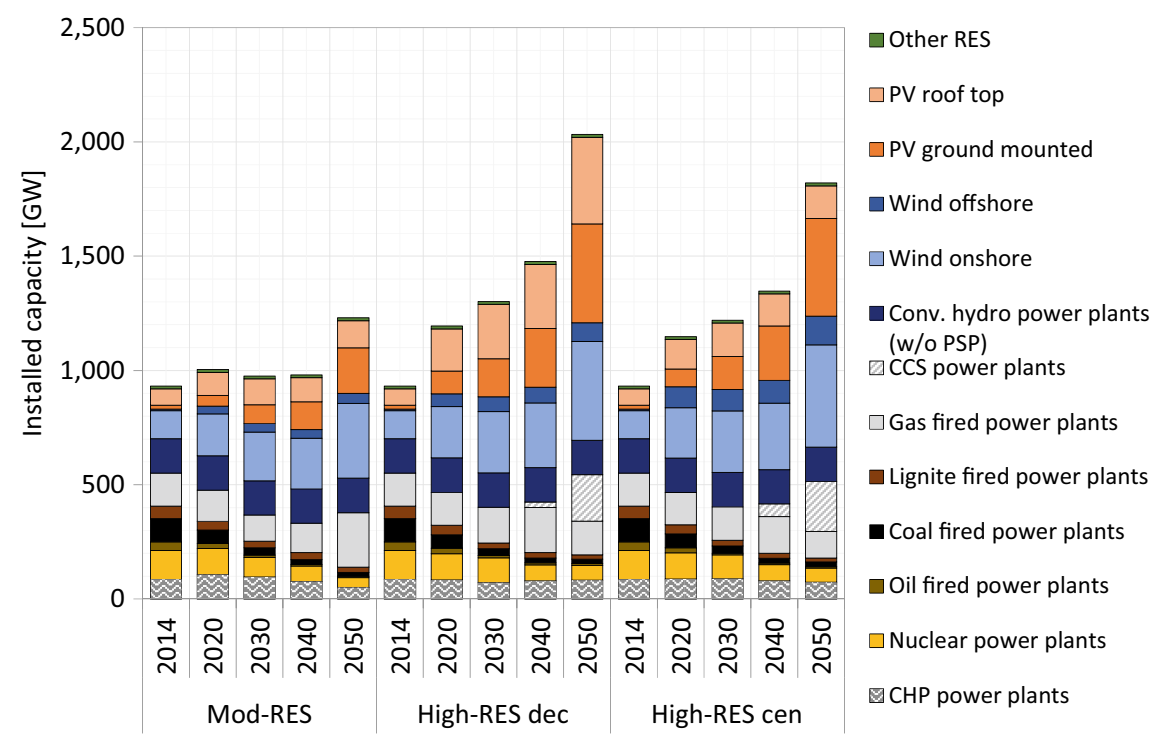

Fig. 10.4 Installed electricity generation mix across all modeled countries (EU-27, Norway, Switzerland, United Kingdom, and the Balkan countries) (Source Data according to own calculations by applying the model ELTRAMOD)

whereas in the centralized scenario optimal investments account for $218 \mathrm{GW}$. As mentioned in the model description in Chapter 3, the investment in new nuclear power plants is restricted to countries, where specific plans for new nuclear power plants exist (e.g., United Kingdom, Poland, and Hungary). This assumption increases the value of alternative low-carbon technologies like CCS to cover the additional electricity demand. In total, the aggregated results for nuclear and CCS-based power plants in the High-RES scenarios are in the range of existing studies, but those often show higher shares of nuclear power plants compared to CCS. For instance, compared to the EU Roadmap (European Commission 2011a), $120 \mathrm{GW}$ of installed capacities for nuclear power plants and $160 \mathrm{GW}$ for CCS plants are estimated. In the EU Reference Scenario, around $93 \mathrm{GW}$ nuclear power plants and 19 GW CCS technologies are installed until 2050 in the European energy system (Capros et al. 2016).

As mentioned before, with increasing $\mathrm{CO}_{2}$ prices as data input, the emission reduction targets within the REFLEX scenario framework are implicitly considered. Figure 10.5 shows the development of the $\mathrm{CO}_{2}$ emissions until 2050 for each scenario in the electricity sector, based on the dispatch of the power plant mix presented before. $\mathrm{CO}_{2}$ emissions decrease significantly in all scenarios and are higher in the Mod-RES scenario compared to the High-RES scenario due to larger shares of generation technologies with higher $\mathrm{CO}_{2}$ emission factors. In the decentralized scenario, more $\mathrm{CO}_{2}$ is emitted compared to the centralized scenario because of more carbon-intensive electricity generation caused by higher electricity demand (cf. Fig. 10.1) and lower RES capacity credits within the PV dominated decentralized system. The increase 


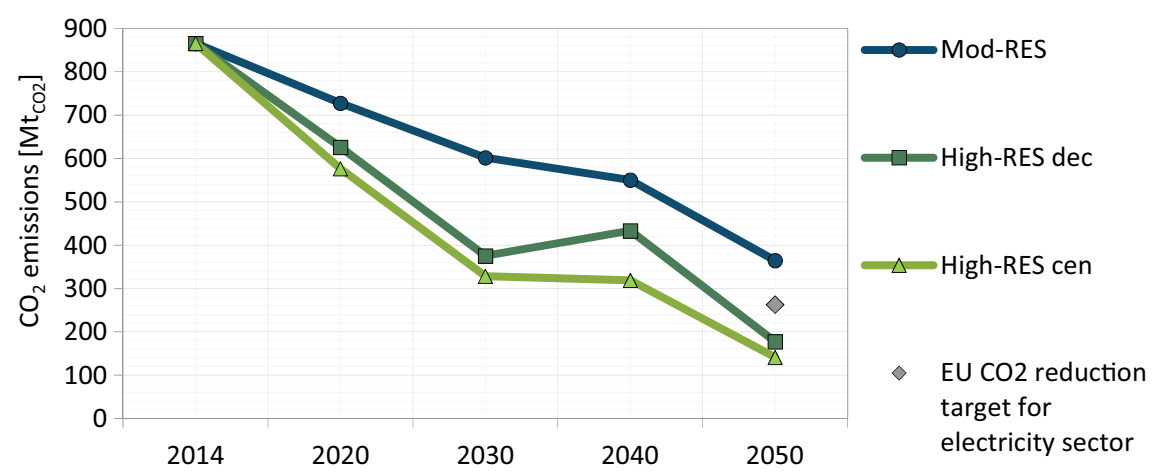

Fig. 10.5 Development of total $\mathrm{CO}_{2}$ emissions in the electricity sector across all modeled countries (EU-27, Norway, Switzerland, United Kingdom, and the Balkan countries) (Source Data according to own calculations by applying the model ELTRAMOD)

of $\mathrm{CO}_{2}$ emissions by 2040 in the decentralized scenario results from the increase of electricity generation from closed-cycle gas turbines (CCGT) due to higher electrification of demand side sectors compared to the centralized scenario. The further decrease of $\mathrm{CO}_{2}$ emissions by 2050 results from the gas-fired technology switch from CCGT to gas-fired CCS generation. The approximately estimated $\mathrm{CO}_{2}$ reduction target of the EU (European Environment Agency 2019) for the electricity sector is about $236 \mathrm{Mt}_{\mathrm{CO} 2}$, which is achieved in both High-RES scenarios. ${ }^{4}$

\subsubsection{Storages}

An economic potential for storage technologies in the electricity market only arises, when the residual load is fluctuating between high and low phases, resulting in hours with high (discharging storage plant) and low (charging storage plant) electricity prices. By temporarily shifting electricity generation and demand, storages theoretically compete with power plants, particularly in the presence of higher RES shares (Zerrahn and Schill 2017; Zöphel and Möst 2017). As shown in Sect. 10.2, although the RES share is rising, the substantial increase in electricity demand, resulting from sector coupling particularly in the High-RES scenarios, rarely leads to low or even negative residual loads. In the following, the influence of these cross-sectoral interactions is analyzed in detail.

In Fig. 10.6, the outcomes based on ELTRAMOD regarding the storage technologies are presented together with the results from eLOAD (namely residential PVbattery systems) to compare the capacities across sectors (cf. Chapter 7). Although

\footnotetext{
${ }^{4}$ More ambitious $\mathrm{CO}_{2}$ emission reduction targets have been agreed with the European Green Deal, and most likely the power sector will also receive a more ambitious sector-specific $\mathrm{CO}_{2}$ emission reduction target, although this has not yet been officially defined.
} 


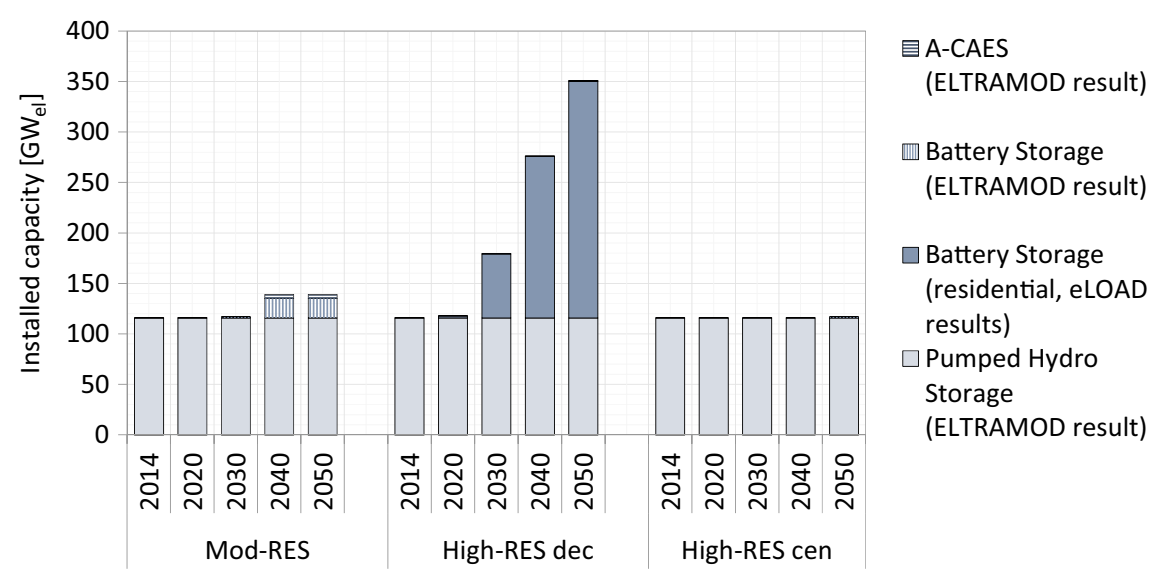

Fig. 10.6 Installed storage capacities across all modeled countries (EU-27, Norway, Switzerland, United Kingdom, and the Balkan countries) (Source Data according to own calculations by Fraunhofer ISI and TU Dresden with the models eLOAD and ELTRAMOD)

batteries from electric vehicles (EV) have a storage capacity, there is no vehicleto-grid technology assumed in eLOAD, thus only a shift of the charging time is possible. Therefore, EV storages are excluded in Fig. 10.6. Besides the existing but not expansible pump storage plant (PSP) capacities accounting for around 120 $\mathrm{GW}$, significant electricity market-based investments in additional storage capacities can only be observed in the Mod-RES scenario, where small lithium-ion batteries (around $18 \mathrm{GW}$ ) and to a lesser extent adiabatic compressed air energy storages (A-CAES) (4 GW) are installed. This reflects the comparably higher variability of the residual load, since the electricity system load curve is less flattened by decentral DSM measures. In the High-RES decentralized scenario, residential PV-battery systems are dominating the storage mix. Nevertheless, their application is to increase residential self-consumption, resulting in a flattened overall residual load. Whereas, in the centralized scenario the load curve is smoothed to a lesser extent by flexible loads (cf. Fig. 10.2). Furthermore, the high intermittent wind shares in the centralized scenario increases the potential for spatial compensation effects which leads to an increasing importance of electricity grid expansion.

In addition to the smoothing effect of the residual load by storages and further DSM measures in the residential sector, sector coupling increases the residual load from a residential (e.g., local heat pumps) and system (district heat pumps, powerto-gas) perspective, particularly in times with negative residual loads. Therefore, missing surplus phases and arbitrage applications decrease the value of electricity market-based storage investments and result in low additional model-endogenous storage capacities. 


\subsection{Sensitivity Analyses}

To further assess the cross-sectoral interaction of electricity market-based storage investments with DSM measures (including PV-battery systems), a sensitivity analysis with no assumed DSM potential on residential level is described in the following Sect. 10.4.1. Additionally, a cost reduction in battery storages and its impact on storage investments is investigated. A further sensitivity analysis is applied in Sect. 10.4.2 to determine the impact of higher weather-dependent RES shares on the mix of flexibility options discussed before.

\subsubsection{Impact of Limited DSM Potential and Reduced Battery Investment Costs on the Storage Value in the Electricity Market}

The sensitivity analysis is applied for the High-RES scenarios, since here the strongest effects are expected. In Fig. 10.7 the sorted residual load curves with and without DSM measures as well as for the reference year 2014 are compared for each the decentralized and centralized scenario.
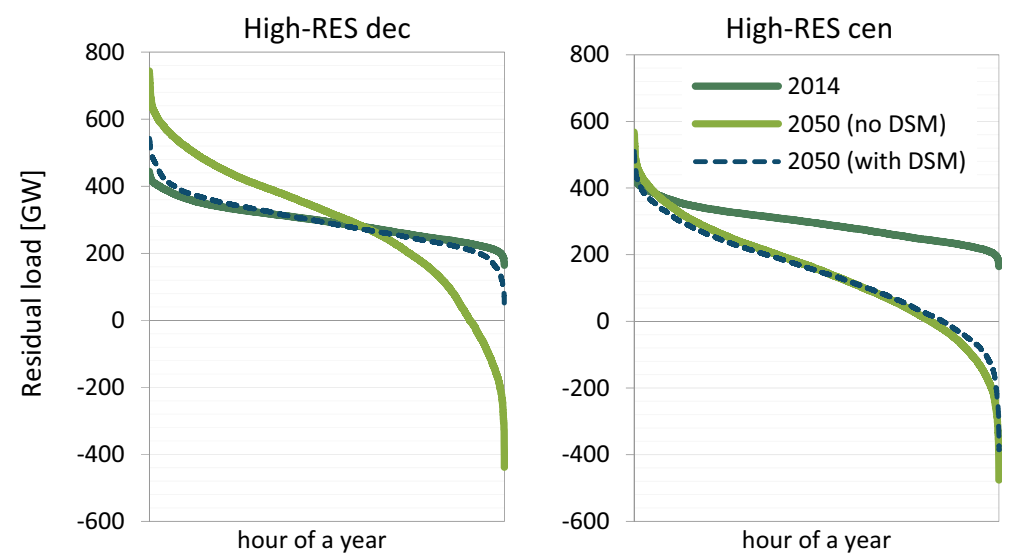

Fig. 10.7 Sorted residual load with and without smoothing effect of DSM applications across all modeled countries (EU-27, Norway, Switzerland, United Kingdom, and the Balkan countries) in 2050 compared to 2014 (The optimal dispatch of central electrolyzers is an ELTRAMOD model result [not an input parameter, therefore not considered in Fig. 10.7] leading to load increase mainly in hours with low or even negative residual load in 2050 [with DSM], resulting in a similar development of the smoothed decentralized residual load in 2050 [with DSM]) (Source Data according to own calculations. The hourly system load data are model outputs from eLOAD calculated by Fraunhofer ISI. The RES generation profiles are calculated by KIT-IIP as described in Slednev et al. [2018]) 
While in both scenarios, the electricity demand is increasing until 2050, the differences between the decentralized and centralized scenario framework regarding the deployment of DSM measures become obvious in Fig. 10.7. The extensive application of DSM measures in the decentralized scenario results in a smoothed residual load similar to the curve of the year 2014 (cf. dark green and blue dashed line). Without exploiting this DSM potential, the curve becomes steeper with more extreme positive and negative peaks. Additional to the stronger use of the DSM potential, this scenario is characterized by decentral hydrogen production resulting in an overall increased residual load. In contrast, the flexibility potential of hydrogen electrolysis in the centralized scenario in the transport and industry sector is not included in the bundle of DSM applications as it is in the decentralized scenario. Furthermore, a comparatively low DSM potential is assumed in the model due to lower societal acceptance for e.g., electromobility, PV-battery systems, heat pumps in the residential and tertiary sector (by assumptions). As mentioned before, the central electrolyzers directly participate in the electricity market in the centralized scenario. Therefore, the investment and dispatch decisions regarding central electrolyzers are a modelendogenous result from ELTRAMOD. This leads to a steeper sorted residual load in the centralized scenario with only small differences between the residual load curve with and without the smoothing effect of DSM for the year 2050.

In an additional sensitivity analysis, specific investment cost reductions by $50 \%$ are assumed for the four battery storage types (small, medium, and large lithium-ion and redox-flow) based on the derived learning curves (cf. Chapter 4). Table 10.1 compares the assumed specific investment costs for these storage types for the year 2050 .

Figure 10.8 shows the results regarding the model-endogenous installed conventional capacities (left ordinate) and storages (right ordinate with different axis scaling) including pump storage plants, adiabatic compressed air energy storages as well as battery storages. With reduced investment costs, additional batteries are installed in 2040 and 2050 (mainly redox-flow batteries), particularly in High-RES centralized.

Table 10.1 Specific investment costs and cost reductions for battery storage technologies in 2050

\begin{tabular}{l|l|l|l}
\hline & Storage capacity & $\begin{array}{l}\text { Specific investment cost } \\
\text { in } 2050\end{array}$ & $\begin{array}{l}\text { Specific investment cost } \\
\text { with 50\% reduction in } \\
2050\end{array}$ \\
\hline $\begin{array}{l}\text { Small lithium-ion } \\
\text { battery }\end{array}$ & 1 & 199 & {$[1,000$ EUR/MW] } \\
\hline $\begin{array}{l}\text { Medium lithium-ion } \\
\text { battery }\end{array}$ & 4 & 694 & 100 \\
\hline $\begin{array}{l}\text { Large lithium-ion } \\
\text { battery }\end{array}$ & 10 & 1,684 & 347 \\
\hline Redox-flow battery & 10 & 752 & 842 \\
\hline
\end{tabular}

Source Data based on learning curves from Louwen et al. (2018) and Chapter 4 


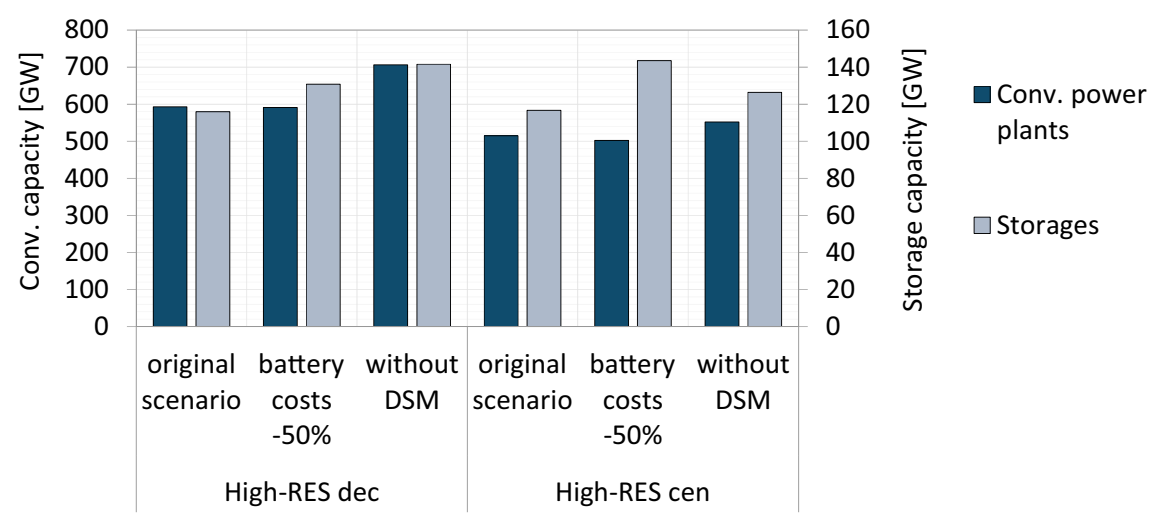

Fig. 10.8 Impact of reduced specific investment costs for storages and no DSM measures on the capacity expansion of conventional power plants and storages across all modeled countries in 2050 (EU-27, Norway, Switzerland, United Kingdom, and the Balkan countries) (Source Data according to own calculations by applying ELTRAMOD)

Regarding the competition with the conventional power plants, Fig. 10.8 shows that only a small amount of conventional capacities can be substituted in both HighRES scenarios. Nevertheless, this effect is higher in the centralized scenario since the structure of the residual load curve (with DSM measures) is more suitable for (centralized) storage applications. As a result, in the High-RES centralized (decentralized) scenario a storage investment cost reduction by $50 \%$ leads to overall additional storage capacities of $27 \mathrm{GW}(15 \mathrm{GW})$ and conventional capacity reductions of $12 \mathrm{GW}(1 \mathrm{GW})$.

Furthermore, for the sensitivity without DSM measures an increase of fossil fuelbased capacities can be observed, since the residual load peaks are increasing significantly, particularly in the decentralized scenario. Additionally, the storage investments are increasing as well. In general, reasons for the low battery storage investments in each sensitivity is the high electrification in other sectors and the competition with power-to-x technologies, particularly for times with low residual loads. The results also show an increase of curtailed RES electricity due to the missing application of DSM. Similar interactions are discussed in the literature (e.g., Müller and Möst 2018). While in the centralized High-RES scenario the RES curtailment increases from $23 \mathrm{TWh}$ (with DSM) to $37 \mathrm{TWh}$ (without DSM), this increase is more pronounced in the decentralized scenario with 0.2 TWh (with DSM) to 43 TWh (without DSM). Nevertheless, the overall curtailment of RES is marginal and below $2 \%$ of the electricity generated by RES. 


\subsubsection{Impact of Higher Shares of Renewable Energy Sources}

A further sensitivity analysis is applied to investigate the impact of higher weatherdependent RES shares on the mix of flexibility options discussed before. This is also done because the original RES shares in the REFLEX scenarios are calculated based on the European electricity demand of the base year 2014. With the crosssectoral electrification of energy demand, the electricity demand in the High-RES scenarios increases from 3,000 TWh to more than 5,000 TWh in 2050. Therefore, electricity generation from wind and PV power plants has to increase to around 4,000 TWh $(5,000 \mathrm{TWh})$ to theoretically cover $80 \%$ (100\%) of this electricity demand. For this sensitivity analysis only the High-RES scenarios are considered to focus on the ambitious RES development pathways, the scenario-specific installed wind and PV capacities are linearly scaled-up for each country.

Table 10.2 illustrates the resulting capacities for the year 2050. The overall installed RES capacities of 1,325 GW (decentralized) and 1,143 GW (centralized) cover around $55 \%$ of the electricity demand in the year 2050 in the original scenarios including electricity for sector coupling. In 2019, approximately $573 \mathrm{GW}$ of renewable capacities are installed with a resulting RES share of approximately $45 \%$ of total electricity consumption and $20 \%$ of gross final energy consumption in the considered countries (Irena 2020). These numbers illustrate the effort still necessary to achieve these high shares of renewables in 2050 by taking sector coupling into account. In the High-RES decentralized scenario, these values have to increase to $1,965 \mathrm{GW}$ and $2,512 \mathrm{GW}$ to achieve a RES share of 80 and $100 \%$ on electricity consumption, respectively. Again, due to the higher shares of wind power plants and their higher availability, the required capacity expansion in the centralized scenario is lower and amounts to $1,586 \mathrm{GW}(80 \%)$ and 2,029 $\mathrm{GW}(100 \%)$.

Table 10.2 Installed wind and PV capacities in the original scenarios and in the sensitivities across all modeled countries in 2050 (EU-27, Norway, Switzerland, United Kingdom, and the Balkan countries)

\begin{tabular}{|c|c|c|c|c|c|c|}
\hline \multirow{2}{*}{$\begin{array}{l}\text { Installed } \\
\text { capacities } \\
{[\mathrm{GW}]}\end{array}$} & \multicolumn{3}{|c|}{ High-RES decentralized } & \multicolumn{3}{|c|}{ High-RES centralized } \\
\hline & Original & $\begin{array}{l}80 \% \text { RES } \\
\text { share }\end{array}$ & $\begin{array}{l}100 \% \text { RES } \\
\text { share }\end{array}$ & Original & $\begin{array}{l}80 \% \text { RES } \\
\text { share }\end{array}$ & $\begin{array}{l}100 \% \text { RES } \\
\text { share }\end{array}$ \\
\hline $\begin{array}{l}\text { Wind } \\
\text { onshore }\end{array}$ & 432 & 641 & 820 & 447 & 623 & 797 \\
\hline $\begin{array}{l}\text { Wind } \\
\text { offshore }\end{array}$ & 82 & 119 & 152 & 125 & 169 & 216 \\
\hline $\begin{array}{l}\mathrm{PV} \text { ground } \\
\text { mounted }\end{array}$ & 433 & 643 & 823 & 428 & 595 & 762 \\
\hline PV rooftop & 378 & 561 & 718 & 143 & 199 & 254 \\
\hline Total & 1.325 & 1.965 & 2.512 & 1.143 & 1.586 & 2.029 \\
\hline
\end{tabular}




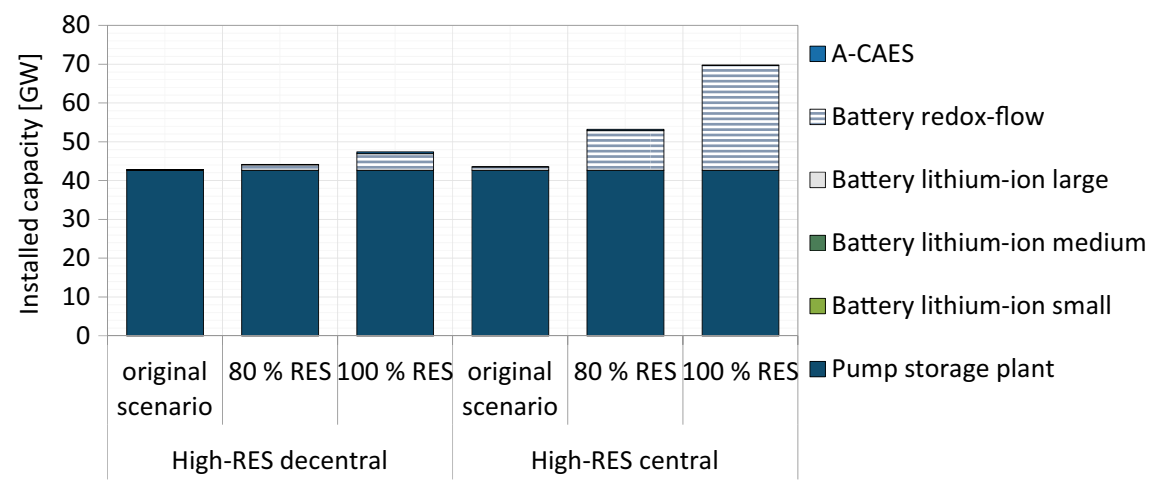

Fig. 10.9 Impact of higher RES shares on investments in storage capacities across all modeled countries in 2050 (EU-27, Norway, Switzerland, United Kingdom, and the Balkan countries) (Source Data according to own calculations by applying ELTRAMOD)

With these wind and PV capacities and the respective electricity generation, optimal investments and dispatch in conventional power plants, storages and powerto-x technologies are model-endogenously calculated with ELTRAMOD, while all other input data and assumptions remain unchanged. The results show that for each scenario conventional, thus dispatchable capacities are still necessary to cover the positive peak residual load. Nevertheless, in both High-RES scenarios the aggregated capacities are decreasing from more than $500 \mathrm{GW}$ in the original scenario to around $440 \mathrm{GW}$ with an $80 \%$ RES share and to around $400 \mathrm{GW}$ with a $100 \%$ RES share. Since the residual load curve is characterized by more very low and negative hours, storages become more valuable with increasing RES shares and can substitute power plant capacities.

Figure 10.9 shows the storage capacities for the year 2050 with different RES shares. In the High-RES centralized scenario, the additional storage capacities are highest with up to $27 \mathrm{GW}$ (100\% RES share), since the residual load is steeper. In general, redox-flow batteries are installed, mainly to balance short-term fluctuations.

It becomes obvious that dispatch of power plants mainly covers periods with high residual load, when analyzing the aggregated electricity generation and demand in the different sensitivities for the year 2050 (cf. Fig. 10.10). Compared to the original scenario, fossil fuel-based (conventional) electricity generation is reduced by 70 $75 \%$ at a RES share of $100 \%$ in both scenarios. Analyzing the $\mathrm{CO}_{2}$ emissions, the higher RES shares from $80 \%$ and $100 \%$ (without curtailment) lead to further emission reduction up to $82 \%$ and $74 \%$ in the decentralized and centralized scenario, respectively, compared to the original scenario results. Nevertheless, also the curtailed amount of wind and PV electricity is increasing up to $12 \%$ of total RES generation, thus decreasing the effective RES share to around $90 \%$. 


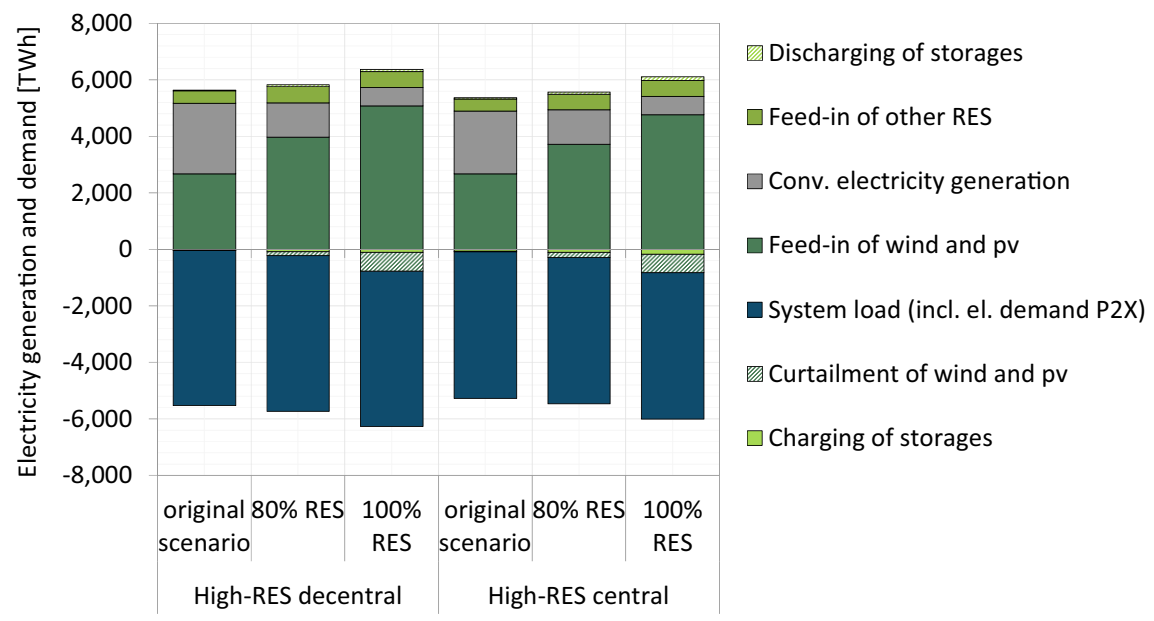

Fig. 10.10 Impact of higher RES share on aggregated electricity generation and demand across all modeled countries in 2050 (EU-27, Norway, Switzerland, United Kingdom, and the Balkan countries) (Source Data according to own calculations by applying ELTRAMOD)

\subsection{Levelized Costs of Electricity and $\mathrm{CO}_{2}$ Abatement Costs}

Figure 10.11 illustrates the total system cost increase of the electricity system as well as the $\mathrm{CO}_{2}$ emission reductions from 2014 to 2050 for all scenarios. The system costs include annualized capital costs, fixed and variable operation and maintenance

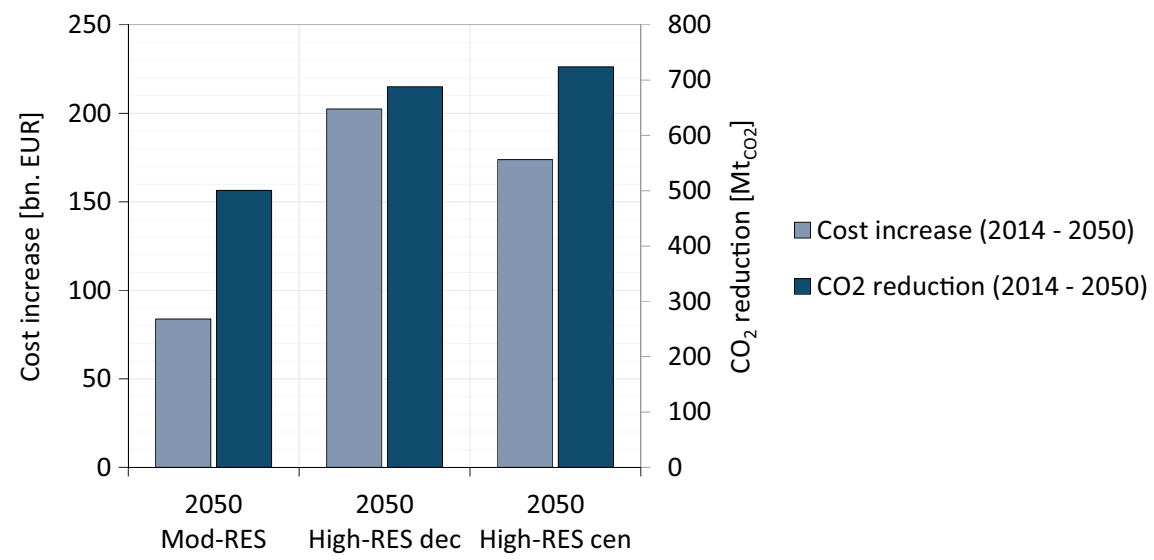

Fig. 10.11 Total yearly system cost increase and $\mathrm{CO}_{2}$ emission reduction in the electricity sector across all modeled countries in 2050 (EU-27, Norway, Switzerland, United Kingdom, and the Balkan countries) (Source Data according to own calculations by applying ELTRAMOD) 


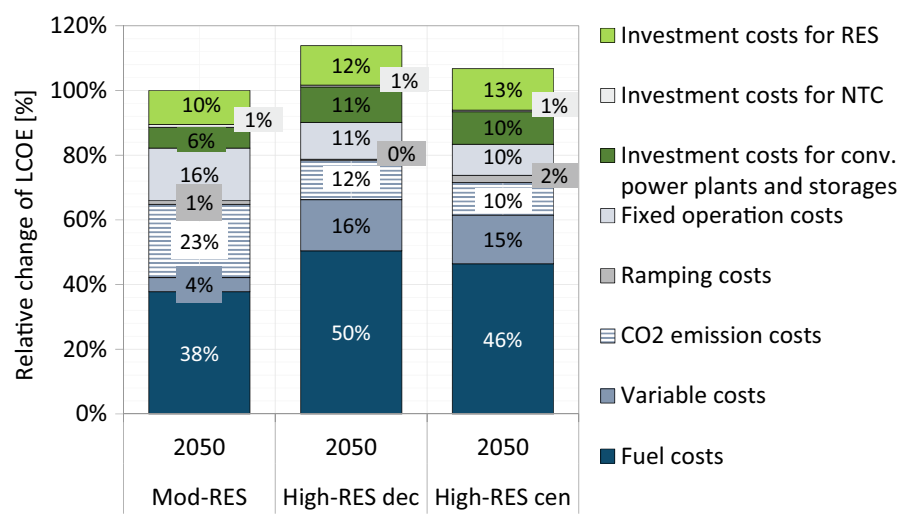

Fig. 10.12 Relative change of levelized costs of electricity (LCOE) for the power sector across all modeled countries in 2050 (EU-27, Norway, Switzerland, United Kingdom, and the Balkan countries) (Source Data according to own calculations by applying ELTRAMOD)

costs, fuel as well as $\mathrm{CO}_{2}$ emission allowance costs. The High-RES centralized scenario shows the highest $\mathrm{CO}_{2}$ emission reduction and simultaneously a lower cost increase from 2014 to 2050 than the High-RES decentralized scenario. The ModRES scenario achieves lower system costs, but realizes less $\mathrm{CO}_{2}$ emission reduction than both High-RES scenarios (cf. Fig. 10.5).

In this chapter, the levelized costs of electricity (LCOE) are defined as total system costs per unit of electricity generated. Figure 10.12 summarizes the LCOE for all electricity generating technologies, storages as well as the investment costs for net transfer capacities (NTC). To compare the scenarios, the LCOE are normalized to the value of the Mod-RES scenario. Both High-RES scenarios have higher fuel costs compared to the Mod-RES scenario due to the significant increase of electricity demand caused by the enforced sector coupling.

However, due to the dispatch of more low-carbon technologies, such as gas-fired CCS plants, the share of $\mathrm{CO}_{2}$ emission costs is lower than in the Mod-RES scenario, although the $\mathrm{CO}_{2}$ price increases significantly from ca. $90 \mathrm{EUR} / \mathrm{t}_{\mathrm{CO} 2}$ in the Mod-RES scenario to approx. 150 EUR/ $\mathrm{t}_{\mathrm{CO} 2}$ in the High-RES scenarios in 2050. The High-RES decentralized scenario has the highest LCOE due to more electricity generation to cover higher electricity demand. Hence, the LCOE are $+14 \%$ and $+7 \%$ higher in the decentralized and centralized High-RES scenario, respectively, compared to the Mod-RES scenario (cf. Fig. 10.12).

High $\mathrm{CO}_{2}$ prices and the resulting incentives for optimal investments in lowcarbon technologies reduce overall $\mathrm{CO}_{2}$ emission costs. With the additional electricity demand due to sector coupling in the High-RES scenarios, the overall RES share is similar to the Mod-RES scenario. However, the higher RES capacities required to cover a higher electricity demand only slightly increase the share of RES investment costs, while the costs associated with the fossil-fuel-based backup capacity (fuel costs, variable costs, and investment costs for conventional power 
plants) are increasing more significantly in the High-RES scenarios. This further underlines the potential benefit of additional RES capacities regarding the average LCOE.

\subsection{Discussion and Conclusion}

This chapter analyzes the fundamental changes in the context of a decarbonized electricity sector with cross-sectoral interdependencies between different demand and supply sectors considering the deployment of RES. For the analysis of an optimal flexibility provision in different European least-cost decarbonization pathways, the fundamental electricity market model ELTRAMOD is applied and embedded in the EMS of the REFLEX project. The normative REFLEX scenario framework illustrates the complexity of the future energy system transformation in Europe with possible overlapping development pathways regarding the RES expansion, the level and implementation approaches for sector coupling as well as different levels of flexibility provision.

The results in this chapter highlight the crucial cross-sectoral interactions and their influence on optimal investment and dispatch decisions for different flexibility options from an electricity market perspective. The analysis shows, that the leastcost efficient capacity mix depends on different deployments of DSM appliances. It can be observed that flexible measures in the demand side sectors decrease the value of flexibility options in the electricity market. Since DSM smooths the residual load, electricity market-based storages decrease in value. Nevertheless, an extensive application of DSM, as in the High-RES decentralized scenario, can lead to significant reductions of positive residual load peaks, thus limiting the need for additional (conventional) back-up capacities. These results support the scientific literature (Müller and Möst 2018; Strbac et al. 2012).

Additionally to the interactions with DSM applications, storages are particularly affected by cross-sectoral electrification. Since an electricity demand increase lowers the frequency of low or negative residual loads, incentives for wholesale marketbased storage technologies are also reduced. At the same time, sector coupling in combination with less ambitious RES expansion, increases the required conventional power plant capacities. Of high importance regarding the optimal flexibility mix in the power system is also the implementation of power-to-x technologies. A marketbased dispatch of investment cost-intensive technologies (e.g., electrolyzers), tends to maximize full load hours of these technologies, and thus rather increase flexibility needs in the electricity sector, mainly provided by additional power plant capacities. In contrast, particularly low capital costs technologies, such as electric boilers and heat pumps in combination with the respective storages, enable a cross-sectoral flexibility provision.

In general, the modeling results indicate, that under the given scenario framework and the input from the model coupling within REFLEX, besides new flexibility options such as DSM and storages, back-up capacities are still necessary to 
provide system flexibility. The ELTRAMOD results underline the crucial role of high $\mathrm{CO}_{2}$ prices to achieve the emission reduction targets. Although the High-RES scenarios are characterized by relatively high shares of $\mathrm{RES}, \mathrm{CO}_{2}$ prices higher than $70 \mathrm{EUR} / \mathrm{t}_{\mathrm{CO} 2}$ are required to enforce decarbonization by avoiding investments in carbon-intensive generation technologies in the presence of an increasing electrification of the demand side sectors. High fuel and $\mathrm{CO}_{2}$ prices can incentivize the competitiveness of low-carbon technologies like gas-fired CCS and flexibility options, such as storages and power-to-x. These results support existing analyses and policy recommendations, e.g., EU Roadmap (European Commission 2011a). The insights gained in this chapter call for the improvement of the EU Emission Trading Scheme (ETS) to enable such high $\mathrm{CO}_{2}$ prices, to provide more long-term clarity and certainty in price developments as well as to include more $\mathrm{CO}_{2}$ emitting sectors. Nevertheless, an even more ambitious RES expansion allows for additional significant reductions in fossil fuel-based electricity generation and the same time increase the value for storage technologies. Only high shares of RES allow for a mix of various flexibility options in the electricity market in a cross-sectoral energy system.

To summarize, the installed flexibility option mix in the electricity market is strongly influenced by the electricity demand and RES feed-in as well as by the sector coupling of the demand side sectors. Differences occur regarding the optimal mix of flexible power plants between the Mod-RES and High-RES scenarios. The combinations of the interactions discussed above result in a rather similar power plant mix in the two High-RES scenarios, although the scenarios are defined by different feed-in characteristics of varying combinations of fluctuating generation from wind and photovoltaic. For the High-RES scenarios, the achievable emission reductions in the present scenario framework and EMS exceed the reduction targets of the European Commission, while the LCOE are increasing rather moderately compared to the Mod-RES scenario. As shown in this analysis, high $\mathrm{CO}_{2}$ prices, preferably above $70 \mathrm{EUR} / \mathrm{t}_{\mathrm{CO} 2}$, and high RES shares are a no-regret strategy to achieve the EU emission reduction targets of at least 80-95\% in 2050 (compared to the level of 1990)..$^{5}$ Accordingly, the optimal combination of flexibility options gains in importance in order to facilitate a high integration of intermittent RES.

\section{References}

Bertsch J, Growitsch C, Lorenczik S, Nagl S (2016) Flexibility in Europe's power sector-an additional requirement or an automatic complement? Energy Econ 53:118-131. https://doi.org/ 10.1016/j.eneco.2014.10.022

\footnotetext{
${ }^{5}$ The European Green Deal, published after the completion of this project, sets more ambitious targets for reducing $\mathrm{CO}_{2}$ emissions, and most likely the power sector will also be affected by these ambitious targets in the near future.
} 
Brown T, Schlachtenberger D, Kies A, Schramm S, Greiner M (2018) Synergies of sector coupling and transmission reinforcement in a cost-optimised, highly renewable European energy system. Energy 16:720-739. https://doi.org/10.1016/j.energy.2018.06.222

Brunner C, Michaelis J, Möst D (2015) Competitiveness of different operational concepts for powerto-gas in future energy systems. Z EnergWirtsch 39(275):293. https://doi.org/10.1007/s12398015-0165-0

Capros P, De Vita A, Tasios N, Siskos P, Kannavou M, Petropoulos A, Evangelopoulou S, Zampara M, Papadopoulos D, Paroussos L, Fragiadakis K, Tsani S, Fragkos P, Kouvaritakis N, HöglundIsaksson L, Winiwarter W, Purohit P, Gomez-Sanabria A, Frank S, Forsell N, Gusti M, Havlík P, Oberstei M, Witzke HP (2016) Kesting M (2016) EU reference scenario 2016-energy, transport and GHG emissions-trends to 2050. European Commission, Brussels

European Commission (2011a) A Roadmap for moving to a competitive low carbon economy in 2050. Communication from the commission to the European Parliament, the Council, the European Economic and Social Committee and the Committee of the Regions. COM (2011)112 final, Brussels

European Environment Agency (2019) Total greenhouse gas emission trends and projections. Online at: https://www.eea.europa.eu/data-and-maps/indicators/greenhouse-gas-emissiontrends-6/assessment-2 (Accessed 29 March 2019)

Hobbie H, Schmidt M, Möst D (2019) Windfall profits in the power sector during phase III of the EU ETS: interplay and effects of renewables and carbon prices. J Clean Prod. https://doi.org/10. 1016/j.jclepro.2019.118066

Irena (2020) Renewable capacity statistics 2020. Renewable Energy Agency (IRENA), Abu Dhabi

Irena (2018) Renewable energy prospects for the European Union. Renewable Energy Agency (IRENA), Abu Dhabi

Ladwig T (2018) Demand side management in Deutschland zur Systemintegration erneuerbarer Energien. Technische Universität Dresden

Louwen A, Krishnan S, Derks M, Junginger M (2018) D3.2 Comprehensive report on Experience curves, REFLEX project report

Michaelis J, Müller T, Reiter U, Fermi F, Wyrwa A, Chen Y, Zöphel C, Kronthaler N, Elsland R (2017) Comparison of the techno-economic characteristics of different flexibility options in the European energy system, 14th International Conference on the European energy market (EEM), Dresden. https://doi.org/10.1109/eem.2017.7981983

Müller T, Möst D (2018) Demand response potential: available when needed? Energy Policy 115:181:198. https://doi.org/10.1016/j.enpol.2017.12.025

Schubert DKJ (2016) Bewertung von Szenarien für Energiesysteme: Potenziale. Technische Universität Dresden, Grenzen und Akzeptanz

Slednev V, Bertsch V, Ruppert M, Fichtner W (2018) Highly resolved optimal renewable allocation planning in power systems under consideration of dynamic grid topology. Comput. Oper. Res. https://doi.org/10.1016/j.cor.2017.12.008

Strbac G, Aunedi M, Pudjianto D, Djapic P, Teng F, Sturt A, Jackravut D, Sansom R, Yufit V, Brandon N (2012) Strategic Assessment of the Role and Value of Energy Storage Systems in the UK Low Carbon Energy Future. London. https://doi.org/10.13140/rg.2.1.1418.5684

Zerrahn A, Schill WP (2017) Long-run power storage requirements for high shares of renewables: review and a new model. Renewable and Sustainable Energy Reviews 79:1518-1534. https://doi. org/10.1016/j.rser.2016.11.098

Zöphel C, Möst D (2017) The value of energy storages under uncertain CO2-prices and renewable shares. In: IEEE Conference Proceedings: 14th International Conference on the European Energy Market-EEM 2017

Zöphel C, Schreiber S, Müller T, Möst D (2018) Which flexibility options facilitate the integration of intermittent renewable energy sources in electricity systems? Current Sustainable/Renewable Energy Reports 5(37):37-44. https://doi.org/10.1007/s40518-018-0092-x 
Zöphel C, Schreiber S, Herbst A, Klingler AL, Manz P, Heitel S, Fermi F, Wyrwa A, Raczyński M, Reiter U, Möst D (2019) Report on cost optimal energy technology portfolios for system flexibility in the sectors heat, electricity and mobility. REFLEX project report

Open Access This chapter is licensed under the terms of the Creative Commons Attribution 4.0 International License (http://creativecommons.org/licenses/by/4.0/), which permits use, sharing, adaptation, distribution and reproduction in any medium or format, as long as you give appropriate credit to the original author(s) and the source, provide a link to the Creative Commons license and indicate if changes were made.

The images or other third party material in this chapter are included in the chapter's Creative Commons license, unless indicated otherwise in a credit line to the material. If material is not included in the chapter's Creative Commons license and your intended use is not permitted by statutory regulation or exceeds the permitted use, you will need to obtain permission directly from the copyright holder. 